\title{
Mutation of a NCKX Eliminates Glial Microdomain Calcium Oscillations and Enhances Seizure Susceptibility
}

\author{
Jan E. Melom and J. Troy Littleton \\ The Picower Institute for Learning and Memory, Department of Biology and Department of Brain and Cognitive Sciences, Massachusetts Institute of \\ Technology, Cambridge, Massachusetts 02139
}

Glia exhibit spontaneous and activity-dependent fluctuations in intracellular $\mathrm{Ca}^{2+}$, yet it is unclear whether glial $\mathrm{Ca}^{2+}$ oscillations are required during neuronal signaling. Somatic glial $\mathrm{Ca}^{2+}$ waves are primarily mediated by the release of intracellular $\mathrm{Ca}^{2+}$ stores, and their relative importance in normal brain physiology has been disputed. Recently, near-membrane microdomain $\mathrm{Ca}^{2+}$ transients were identified in fine astrocytic processes and found to arise via an intracellular store-independent process. Here, we describe the identification of rapid, near-membrane $\mathrm{Ca}^{2+}$ oscillations in Drosophila cortex glia of the CNS. In a screen for temperature-sensitive conditional seizure mutants, we identified a glial-specific $\mathrm{Na}^{+} / \mathrm{Ca}^{2+}, \mathrm{K}^{+}$exchanger (zydeco) that is required for microdomain $\mathrm{Ca}^{2+}$ oscillatory activity. We found that zydeco mutant animals exhibit increased susceptibility to seizures in response to a variety of environmental stimuli, and that $z y d e c o$ is required acutely in cortex glia to regulate seizure susceptibility. We also found that glial expression of calmodulin is required for stress-induced seizures in zydeco mutants, suggesting a $\mathrm{Ca}^{2+} /$ calmodulin-dependent glial signaling pathway underlies glial-neuronal communication. These studies demonstrate that microdomain glial $\mathrm{Ca}^{2+}$ oscillations require NCKX-mediated plasma membrane $\mathrm{Ca}^{2+}$ flux, and that acute dysregulation of glial $\mathrm{Ca}^{2+}$ signaling triggers seizures.

\section{Introduction}

Epilepsy is defined by incapacitating episodes of hypersynchronous neuronal firing. Although dysregulation of neuronal ion channel function has been implicated in seizure pathogenesis in a subset of idiopathic epilepsy cases (Klassen et al., 2011), the initial cellular events that trigger a seizure are not well understood. Recently, increased glial $\mathrm{Ca}^{2+}$ activity has been associated with abnormal neuronal excitability in several mammalian models of epilepsy (Tian et al., 2005; Fellin et al., 2006), and cortical astrocytes were found to exhibit $\mathrm{Ca}^{2+}$ oscillations immediately preceding a focal seizure event (Gómez-Gonzalo et al., 2010). However, whether increased glial $\mathrm{Ca}^{2+}$ activity is a result of seizures, or is a direct cause of seizures, is unclear.

Glial $\mathrm{Ca}^{2+}$ oscillations arise spontaneously (Takata and Hirase, 2008) and in response to physiological neuronal activity (Wang et al., 2006). Most experimental studies of glial $\mathrm{Ca}^{2+} \mathrm{ac}^{-}$ tivity have been restricted to measurement of somatic $\mathrm{Ca}^{2+}$ due to the small volume and inaccessibility of fine glial processes to $\mathrm{Ca}^{2+}$-sensitive dyes (Agulhon et al., 2008). However, recent studies using membrane-targeted $\mathrm{Ca}^{2+}$-sensitive GFP (GCaMP) have shown that small, near-membrane $\mathrm{Ca}^{2+}$ oscillations arise in

\footnotetext{
Received Aug. 16, 2012; revised Oct. 19, 2012; accepted Nov. 8, 2012.

Author contributions: J.E.M. and J.T.L. designed research; J.E.M. performed research; J.E.M. and J.T.L. analyzed data; J.E.M. and J.T.L. wrote the paper.

This work was supported by NIH Grants NS43244 to J.T.L. and F31NS076024 to J.M. We thank L. Looger, T. Awasaki, M. Freeman, the Bloomington Drosophila Stock Center at Indiana University, the Vienna Drosophila RNAi Center, and the Harvard TriP for fly strains; and J. Schulte and A. Rodal for helpful discussions.

The authors declare no competing financial interests.

Correspondence should be addressed to J. Troy Littleton at the above address. E-mail: troy@mit.edu.

DOI:10.1523/JNEUROSCI.3920-12.2013

Copyright $\odot 2013$ the authors $\quad 0270-6474 / 13 / 331169-10 \$ 15.00 / 0$
}

astrocytic processes and do not necessarily propagate to the cell body (Shigetomi et al., 2010). The distinction between global, somatic $\mathrm{Ca}^{2+}$ oscillations and small, near-membrane $\mathrm{Ca}^{2+}$ oscillations in glial processes is critical, and may explain differing results concerning the physiological importance of glial $\mathrm{Ca}^{2+}$ signaling in the regulation of neuronal excitability (Fiacco et al., 2007; Petravicz et al., 2008; Agulhon et al., 2010).

Drosophila glia exhibit morphological similarity to their mammalian counterparts (Stork et al., 2012). Mammalian astrocytes occupy spatially segregated domains in the CNS, each encompassing several neuronal cell bodies, and thus appear positioned to regulate local neuronal signaling (Bushong et al., 2002; Halassa et al., 2007). Cortex glia in Drosophila exhibit a similar spatial segregation, with each glial cell ensheathing multiple neuronal soma (Pereanu et al., 2005). Multiple functions originally identified in mammalian glia are conserved in Drosophila, including regulation of axon pathfinding (Spindler et al., 2009), axonal insulation (Banerjee et al., 2006), synaptic pruning (Fuentes-Medel et al., 2009), and modulation of neurotransmission and behavior (Jackson and Haydon, 2008; Ng et al., 2011). Although numerous functional similarities between Drosophila and mammalian glia have been described, the dynamics of $\mathrm{Ca}^{2+}$ signaling and regulation in Drosophila CNS glia are largely unexplored.

Here we show that mutation of a Drosophila glial-specific $\mathrm{Na}^{+} / \mathrm{Ca}^{2+}, \mathrm{K}^{+}$exchanger eliminates microdomain cortex glial $\mathrm{Ca}^{2+}$ oscillations and predisposes animals to seizures in response to several environmental stressors. In addition, we show that acute, in vivo dysregulation of glial $\mathrm{Ca}^{2+}$ triggers rapid neuronal seizures. Our findings identify one of the first glial-specific genes responsible for an epileptic phenotype and indicate that a $\mathrm{Ca}^{2+}$ / 
calmodulin-dependent glial-derived signal is sufficient to initiate seizure activity in the brain.

\section{Materials and Methods}

Drosophila genetics and molecular biology. Flies were cultured on standard medium at $22^{\circ} \mathrm{C}$. zydeco (zyd) mutants were generated by ethane methyl sulfonate (EMS) mutagenesis and identified in a screen for temperature-sensitive (TS) behavioral phenotypes (Guan et al., 2005). $z y d^{1}$ was mapped to the $\mathrm{X}$ heterochromatic region containing CG2893 by recombination and complementation analysis with deficiency chromosomes. Mutation of CG2893 in three independently generated zyd alleles was identified by sequencing and comparison to control genomic sequence. We used the UAS/Gal4 system to drive transgenes in glia. UASzyd was constructed by subcloning the zydeco cDNA into pUAST and injected into $w^{1118}$ by Genetic Services. UAS-myrGCaMP5 was constructed by subcloning the first 90 aa of Src64b, containing a myristoylation target sequence, into pBI-UASc (creating pBI-UASc-myr). GCaMP5G cDNA (Addgene plasmid 31788) was cloned into pBI-UAScmyr and injected using $\phi$-C-31 transformation.

Behavioral assays. Bang sensitivity of adult female flies was assayed 2-3 $\mathrm{d}$ posteclosion. Flies were transferred into empty vials and allowed to rest for 1-2 h. Vials were vortexed at maximum speed for $10 \mathrm{~s}$, and the number of flies that were upright and mobile was counted at $10 \mathrm{~s}$ intervals. For assaying temperature-sensitive phenotypes, 1- to 3-d-old flies were transferred into preheated vials in a water bath held at the indicated temperature with a precision of $0.1^{\circ} \mathrm{C}$. Flies of either sex were analyzed, except in the case of $z y d^{1}$ mutant UAS/Gal4 rescue animals, in which only males were used. Seizures were defined as the condition in which the animal lies incapacitated on its back or side with legs and wings contracting vigorously. Paralysis was defined as the condition in which the animal fell to the bottom of the vial and exhibited no movement. For assaying seizures in larval animals, third instar larvae of either sex were gently washed with PBS and transferred to $1 \%$ agarose plates heated to $38^{\circ} \mathrm{C}$ using a temperature-controlled stage. Larval seizures were defined as continuous, unpatterned contraction of the body wall muscles that prevented normal crawling behavior.

Immunostaining and Western blots. ZYD polyclonal antibodies were generated in rabbit with a synthetic zydeco peptide corresponding to residues 313-329 (DEGRKEEGYSLLSYPKD) and affinity-purified by Yenzym Antibodies. For ZYD immunostaining, dissected third instar larvae of either sex were fixed with $100 \%$ ice-cold methanol for $5 \mathrm{~min}$. Antibodies were used at the following dilutions: rabbit anti-ZYD, 1:1000; rat anti-ELAV 7E8A10 (Developmental Studies Hybridoma Bank), 1:50; rat anti-GFP (Nacalai Tesque), 1:1000; and Cy3- and Cy2-conjugated anti-rabbit and anti-rat (Jackson ImmunoResearch), 1:3000. Larvae were mounted in 70\% glycerol in PBS and imaged on a Zeiss Pascal confocal microscope with Pascal software (Carl Zeiss MicroImaging) with oilimmersion $40 \times 1.3$ numerical aperture (NA) and $63 \times 0.95 \mathrm{NA}$ objectives. Western blotting of adult whole-head lysates was performed using standard laboratory procedure. Nitrocellulose membranes were probed with rabbit anti-calmodulin clone EP799Y (Abgent), 1:500. Equal loading was assayed using anti-tubulin clone B-5-1-2 (Sigma-Aldrich), 1:60,000. Primaries were detected with Alexa Fluor 680-conjugated antirabbit and anti-mouse (Invitrogen). Western blots were visualized in an Odyssey infrared scanner (Li-Cor).

In vivo $\mathrm{Ca}^{2+}$ imaging. UAS-myrGCaMP5 was expressed in glia with repo-Gal4. Second instar male larvae were washed with PBS and placed on a glass slide with a small amount of Halocarbon oil \#700 (LabScientific). Larvae were turned ventral side up and gently pressed with a coverslip and a small iron ring to inhibit movement. We acquired images with a PerkinElmer Ultraview Vox spinning disk confocal microscope and a high-speed EM CCD camera at $8-12 \mathrm{~Hz}$ with a $40 \times 1.3 \mathrm{NA}$ oilimmersion objective, using a Volocity Software program. We imaged at a single optical plane within the ventral cortex of the ventral nerve cord (VNC), in the dense cortical glial region immediately below the surface glial sheath. Average myrGCaMP5 signal in cortex glia was quantified in the central abdominal neuromeres of the VNC within a manually selected ROI excluding the midline glia. $\mathrm{Ca}^{2+}$ oscillation frequency was quantified within the first minute of imaging at room temperature in a 2 $\mathrm{mm}^{2}$ region of $\mathrm{VNC}$ cortex per larvae. The average area of a $\mathrm{Ca}^{2+}$ oscillation was quantified during the peak of an oscillatory event $\left(\Delta F / F_{\mathrm{o}}\right.$ $\geq 10 \%$ ). Temperature was controlled using a Tempcontrol $37-1$ analog temperature-regulated stage (Carl Zeiss Microscopy) and monitored with an Ultra Fine flexible microprobe attached to a BAT-12 thermometer (Physitemp Instruments). When indicated, larvae were maintained at $38^{\circ} \mathrm{C}$ for $1 \mathrm{~min}$ before imaging.

Electrophysiology. Current-clamp recordings of wandering third instar larvae were performed in HL3.1 saline (in mM: $70 \mathrm{NaCl}, 5 \mathrm{KCl}, 4 \mathrm{MgCl}_{2}$, $0.2 \mathrm{CaCl}_{2}, 10 \mathrm{NaHCO}_{3}, 5$ Trehalose, 115 sucrose, 5 HEPES-NaOH, pH 7.2) containing $1.5 \mathrm{~mm} \mathrm{Ca}^{2+}$ using an Axoclamp 2B amplifier (Molecular Devices) at muscle fiber 6/7 of segments A1-A4. Larvae were of either sex, except for recordings made in $z y d^{1}$ mutant and control UAS/Gal4 rescue animals, which were always male. For recording the output of the central pattern generator, the CNS and motor neurons were left intact with the ventral nerve cord. Temperature was controlled with a Peltier heating device and continually monitored with a microprobe thermometer. Preparations were maintained at the indicated temperature for 2 min before recording.

\section{Results}

\section{zydeco encodes a glial-specific NCKX that regulates seizure susceptibility}

We identified mutations in $z y d$ in an unbiased screen for recessive TS seizure mutants on the X chromosome (Guan et al., 2005). Using deficiency mapping and positional cloning, we discovered that zyd mutations disrupt the CG2893 locus, which encodes a NCKX (Fig. 1A). NCKX proteins are plasma membrane transporters that export intracellular $\mathrm{Ca}^{2+}$ by using $\mathrm{Na}^{+}$and $\mathrm{K}^{+}$ electrochemical gradients, and have a high transport capacity important for rapid reduction of elevated cytosolic $\mathrm{Ca}^{2+}$ (Altimimi and Schnetkamp, 2007). Two alleles of $z y d$ are point mutations in a highly conserved region of NCKX containing residues essential for cation transport (Winkfein et al., 2003) (Fig. 1B), while a third $\left(z y d^{1}\right)$ creates an early stop codon that removes 2 of the 11 transmembrane domains.

All three z $y d$ mutants are homozygous adult viable and exhibit rapid seizures upon exposure to $38^{\circ} \mathrm{C}$ (Movie 1). TS $z y d$ seizures also occur at the larval stage (Movie 2), consistent with the onset of zyd expression during mid-embryogenesis and continuing through adulthood (Winkfein et al., 2004). We recorded central pattern generator output from the neuromuscular junction (NMJ) of third instar larvae and found that $z y d$ mutants exhibit rapid, unpatterned firing at $38^{\circ} \mathrm{C}$, whereas wild-type larvae retain motor neuron bursting necessary for normal crawling behavior (Fig. 1C,D). Cutting the innervating motor neuron immediately blocks seizure activity recorded at $z y d \mathrm{NMJs}$, indicating the point of seizure initiation is upstream of the neuromuscular synapse.

At room temperature, zyd mutants exhibit seizures and temporary paralysis in response to brief vortexing (known as bangsensitivity), whereas wild-type controls do not (Fig. 1E). Bang sensitivity has been identified in several other Drosophila mutants that exhibit neuronal hyperexcitability and seizures in response to electrical stimulation (Pavlidis and Tanouye, 1995). We also observed that $z y d^{1}$ mutants exhibit robust seizures after a brief period of anesthesia on ice (Movie 3). Collectively, these results indicate that $z y d$ mutants are hyperexcitable and prone to seizure activity triggered by a variety of environmental stimuli.

To determine whether the seizures in $z y d$ are caused solely by mutation of CG2893, we used the UAS/Gal4 system to perform tissue-specific rescue of $z y d$ mutants. Given that $z y d$ mRNA is restricted to the CNS and appears specific to glia rather than neurons (Winkfein et al., 2004; Beckervordersandforth et al., 2008), we tested both pan-neuronal and pan-glial Gal4 drivers for rescue of $z y d$. We found that expression of a UAS-zyd transgene 
A

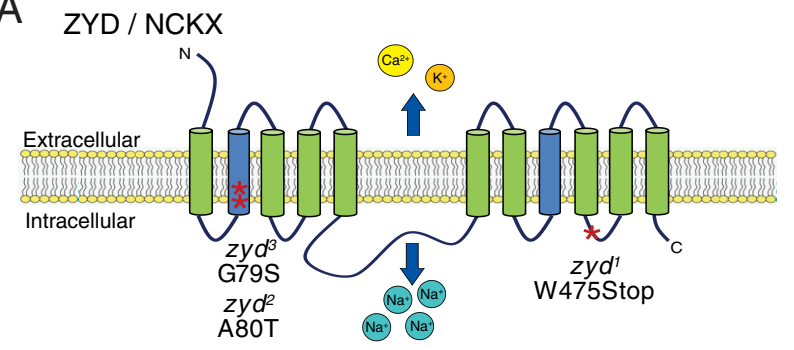

C

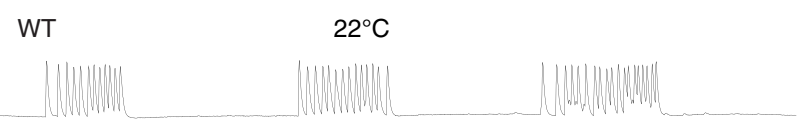

$z y d^{1}$

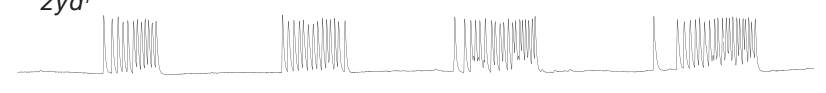

D WT

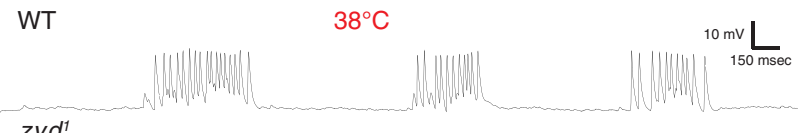

$z y d^{1}$

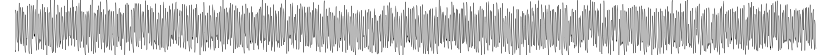

B

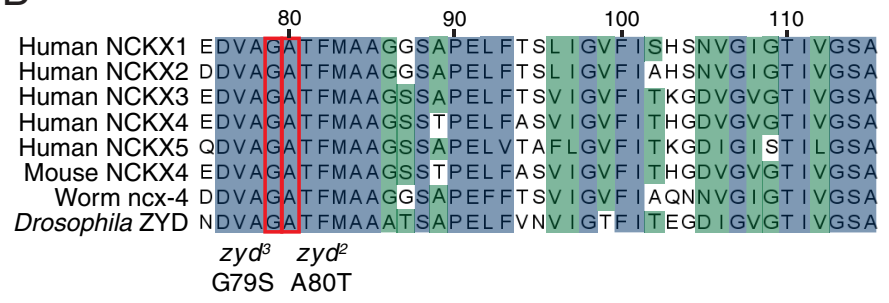

$E$

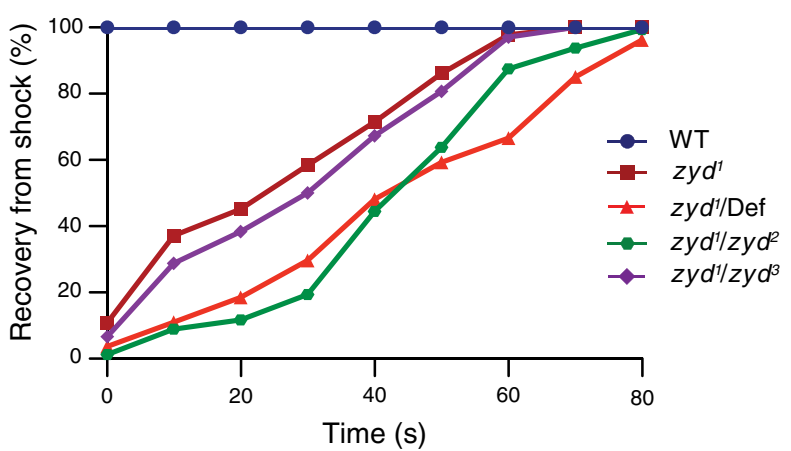

Figure 1. Mutation of the NCKX zyd causes temperature- and bang-sensitive seizures. $A$, EMS-induced mutations isolated in CG2893/NCKX in three independently generated alleles of zyd. Alleles $z y d^{2}$ and zyd ${ }^{3}$ are missense mutations in a pore-lining domain of the exchanger (blue), known as the $\alpha 1$-repeat region. $\boldsymbol{B}$, Alignment of mammalian and invertebrate NCKX $\alpha 1$-repeat regions, indicating $z y d^{2}$ and $z y d^{3}$ mutations (blue $=$ identical, green $=$ similar residues). $C, D$, Representative voltage traces of spontaneous central pattern generator activity at larval third instar muscle 6 at $22^{\circ} \mathrm{C}(\boldsymbol{C})$ and $38^{\circ} \mathrm{C}(\boldsymbol{D})$ in wild-type and zyd ${ }^{1}$ mutants $(n>8$ preparations/genotype). $\boldsymbol{E}$, Recovery time from seizures induced by mechanical stimulation (10 s of vortexing) in WT and zyd mutants at $22^{\circ} \mathrm{C} . n=100$ flies/genotype.

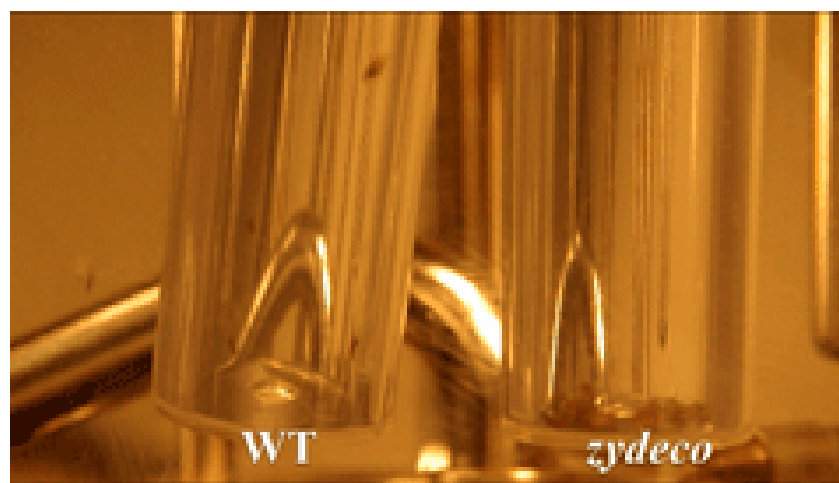

Movie 1. Zyd mutant adults exhibit temperature-sensitive seizures. Wild-type and $z y d^{1}$ mutant adults were transferred into vials preheated in a $38^{\circ} \mathrm{C}$ water bath. Video speed is $3 \times$ real time.

with the pan-glial repo-Gal4 driver fully rescues $z y d^{1}$ mutant TS seizures (Fig. 2A). Pan-neuronal expression with elav-Gal4 does not affect the onset or severity of TS $z y d$ seizures (Fig. 2A), indicating that ZYD is required in glia, and not neurons, to regulate seizure susceptibility.

To determine whether disruption of ZYD expression in glia is sufficient to elicit seizures, we knocked down $z y d$ by RNAi in neurons and glia (Fig. 2B). Pan-glial expression of two unique RNAi hairpins targeting $z y d$ produces TS seizures in third instar larvae and is semilethal in adults. Adult escapers expressing glial zyd RNAi are ataxic and die within several days, indicating that glial $z y d$ expression is critical for nervous system function. Interestingly, expression of $z y d \mathrm{RNAi}$ with $\mathrm{gcm}$-Gal4, a pan-glial driver expressed only during early stages of development (Hosoya et al., 1995), did not recapitulate the $z y d^{1}$ mutant phenotype (Fig. 2C), indicating that constitutive $z y d$ knockdown in mature glia is re-

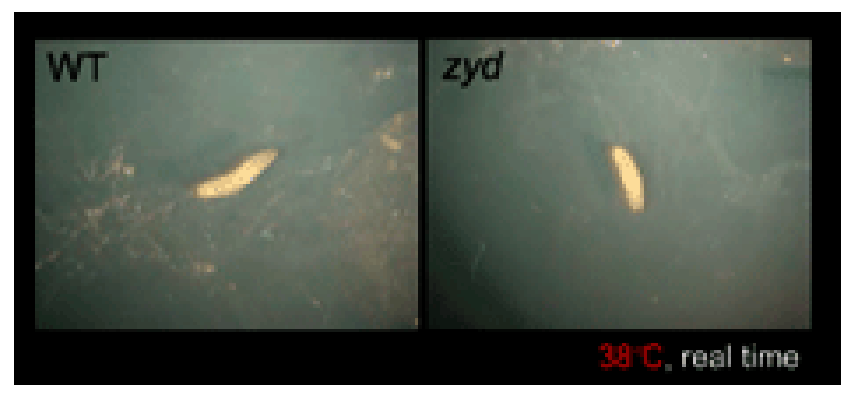

Movie 2. Zyd mutant larvae exhibit temperature-sensitive seizures. Wild-type and zyd mutant third instar larvae were transferred to agarose plates heated to $38^{\circ} \mathrm{C}$. Video starts $30 \mathrm{~s}$ after larvae were transferred to the plate. Video speed is real time.

quired to induce seizure susceptibility. Neuronal knockdown of zyd did not cause any temperature-sensitive behavioral or electrophysiological phenotypes in larvae (Fig. $2 B$ ) or adults. These results indicate that ZYD function in glia is required to regulate neuronal excitability.

\section{ZYD is expressed in cortical glia that encapsulate neuronal cell bodies}

Drosophila glia exhibit distinct morphological subtypes that can be transgenically targeted with specific Gal4 drivers (Awasaki et al., 2008; Doherty et al., 2009), allowing determination of whether ZYD is required in a particular subpopulation of glia. We found that knockdown of zyd by RNAi using four unique Gal4 drivers that express in cortex glia caused strong TS seizures (Fig. $2 B, C)$. We also tested for rescue of $z y d^{1}$ mutant seizures, and found expression of UAS- $z y d$ with several cortex glial Gal4 promoters was sufficient to fully suppress seizures in adult $z y d^{1} \mathrm{mu}-$ tants. Knockdown of $z y d$ in other glial populations, including 


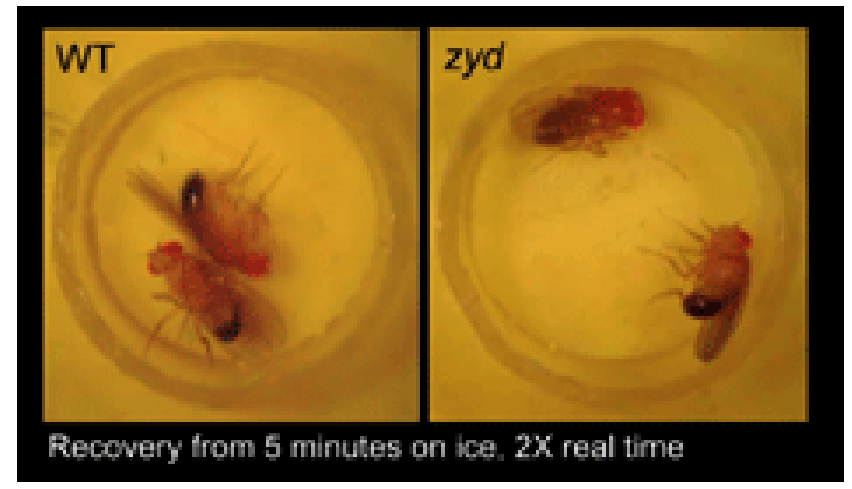

Movie 3. Zyd mutants exhibit seizures upon recovery from cold shock. Wild-type and zyd ${ }^{1}$ mutant adult flies were placed in prechilled vials on ice for $5 \mathrm{~min}$, then were allowed to recover at room temperature (start of video recording). Video speed is $2 \times$ real time.

A

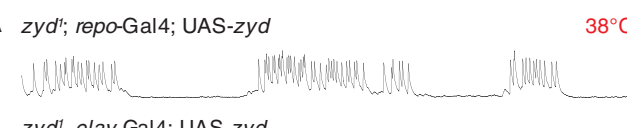

zyd', elav-Gal4; UAS-zyd

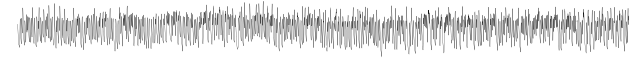

B

Control

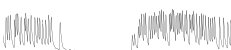

$38^{\circ} \mathrm{C}$

elav-Gal4; UAS-zyd RNAi

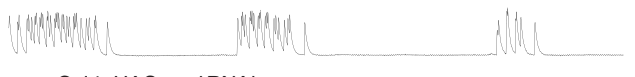

repo-Gal4; UAS-zyd RNAi

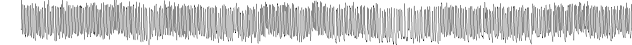

NP2222-Gal4; UAS-zyd RNAi

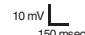

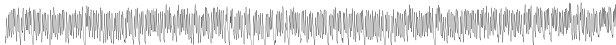

C

\begin{tabular}{|c|c|c|c|}
\hline $\begin{array}{l}\text { Gal4 } \\
\text { Driver }\end{array}$ & Expression & $\begin{array}{l}\text { Rescue } \\
\text { of } z y d^{1} \text { ? }\end{array}$ & $\begin{array}{l}\text { X UAS-zyd } \\
\text { RNAi, } 38^{\circ} \mathrm{C} \\
\end{array}$ \\
\hline repo & Pan-glial & Yes & $\begin{array}{l}\text { Seizures / } \\
\text { semi-lethal }\end{array}$ \\
\hline NP2222 & Cortex glia & Yes & Seizures \\
\hline NP577 & Cortex glia & NT & Seizures \\
\hline nrv2 & $\begin{array}{l}\text { Cortex glia, neuropil } \\
\text { glia (weakly) }\end{array}$ & Yes & Seizures \\
\hline$N P 1243$ & $\begin{array}{l}\text { Astrocyte-like glia, } \\
\text { cortex glia (weakly) }\end{array}$ & Yes & $\begin{array}{l}\text { Intermittent } \\
\text { seizures }\end{array}$ \\
\hline alrm & Astrocyte-like glia & No & Normal \\
\hline dEAAT1 & Astrocyte-like glia & NT & Normal \\
\hline$m z 0709$ & Ensheathing glia & NT & Normal \\
\hline NP6520 & Ensheathing glia & NT & Normal \\
\hline NP6293 & $\begin{array}{l}\text { Surface glia } \\
\text { (perineurial) }\end{array}$ & NT & Normal \\
\hline NP2276 & $\begin{array}{l}\text { Surface glia } \\
\text { (subperineurial) }\end{array}$ & NT & Normal \\
\hline $\mathrm{gcm}$ & $\begin{array}{l}\text { Neuroglioblasts / } \\
\text { glioblasts }\end{array}$ & NT & Normal \\
\hline
\end{tabular}

Figure 2. zyd is required in cortex glia to regulate seizure susceptibility. A, Pan-glial repo-Gal4 driven expression of a wild-type UAS-zyd transgene rescues temperaturesensitive seizures in zyd ${ }^{1}$ mutants, but pan-neuronal elav-Gal4 expression does not. $\boldsymbol{B}$, Knockdown of zyd by pan-neuronal RNAi does not affect central pattern generator activity compared with control at $38^{\circ} \mathrm{C}$, but knockdown of zyd by pan-glial- or cortex glial-driven (NP2222-Gal4) RNAi causes rapid, seizure-like discharges in the larval muscle. $n>5$ preparations/genotype. C, Use of a collection of glial subpopulation specific Gal4 drivers to rescue zyd ${ }^{1}$ TS seizures (with UAS-zyd), or to knockdown zyd (with UAS-zyd RNAi). Only $\mathrm{Gal} 4$ drivers with expression in cortex glia rescued adult $z y d^{1}$ seizures at $38^{\circ} \mathrm{C}$ and phenocopied zyd TS seizures by RNAi. NT, Not tested. $n>50$ animals/genotype. astrocyte-like glia, ensheathing glia, and surface glia, did not cause TS seizures or other obvious behavioral phenotypes.

Cortex glia are highly lamellated cells that form a honeycombed network in the brain, encapsulating individual neuronal cell bodies (Hoyle et al., 1986; Pereanu et al., 2005). Cortex glia are involved in guidance of secondary axon tracts and maintenance of cortical structural integrity (Dumstrei et al., 2003; Spindler et al., 2009), but little is known about their function in the mature nervous system. To verify ZYD expression in cortex glia, we generated antisera to the protein. ZYD immunoreactivity uniformly labels cortex glial membranes in third instar larval CNS, forming chambers that surround clusters of neuronal cell bodies (Fig. $3 A$ ). As development proceeds through metamorphosis, cortex glia in the outer layers of the CNS subdivide these chambers to individually encapsulate the enclosed neurons (Pereanu et al., 2005). In the third instar ventral nerve cord, ZYD staining closely surrounds each neuronal cell body, as revealed by costaining with antibodies against ELAV, a neuronal nuclei-specific protein (Fig. 3B). ZYD staining also closely colocalizes with pan-glial GFP expression in the CNS (Fig. 3C). ZYD immunoreactivity is strongly reduced in both the central brain hemispheres and ventral nerve cord of $z y d^{1}$ mutants.

To verify the specificity of the RNAi hairpins targeting $z y d$, we examined ZYD expression in the CNS of larvae expressing either pan-neuronal, pan-glial, or cortex glial $z y d$ RNAi (Fig. 3D). Neuronal expression of zyd RNAi with elav-Gal4 does not reduce ZYD immunoreactivity, while both pan-glial and cortex glial zyd RNAi abolishes ZYD expression, indicating that ZYD is expressed exclusively in cortex glia in the brain.

\section{ZYD is required acutely in the mature CNS to regulate neuronal excitability}

To discriminate between an acute versus developmental role for ZYD in the CNS, we conditionally expressed a UAS-zyd transgene in $z y d^{1}$ mutants using the $h s p 70$-Gal4 driver (Fig. 4). The conditional $h s p 70$-Gal4 driver is not transcribed at room temperature, but is induced above $30^{\circ} \mathrm{C}$, and is maximally expressed at $36-$ $37^{\circ} \mathrm{C}$ (Lindquist, 1986; Brand et al., 1994). $z y d^{1}$ mutants were raised at $22^{\circ} \mathrm{C}$ from embryogenesis to adulthood, and then subjected to a brief $37^{\circ} \mathrm{C}$ heat pulse to induce expression of UAS- $z y d$. Conditional UAS-zyd transgene expression rescued $z y d^{1}$ TS seizures in adults $6 \mathrm{~h}$ after the heat pulse, consistent with the time course of induced $h s p 70$-Gal4 activity measured after a similar heat treatment (Lindquist, 1986). Susceptibility to TS seizures returned in the conditionally rescued $z y d^{1}$ flies several days after the heat pulse, likely reflecting the rate of ZYD protein turnover. Genetically identical control animals not subjected to a brief heat pulse exhibited TS seizures at all time points tested (Fig. 4, blue bars). These data indicate that restoration of ZYD function in the mature nervous system reduces neuronal excitability, and suggests that seizures arising in $z y d^{1}$ mutants are unlikely to be the result of neuronal miswiring or other developmental defects.

Dynamic microdomain $\mathrm{Ca}^{2+}$ oscillations occur in cortex glia in vivo and are absent in $z y d$ mutants

To observe near-membrane $\mathrm{Ca}^{2+}$ dynamics in cortex glia, we generated a myristoylated variant of $\mathrm{Ca}^{2+}$-sensitive GFP (myrGCaMP5), which targets to the inner leaflet of the plasma membrane (Akerboom et al., 2012). Glial expression of myrGCaMP5 revealed small, rapid $\mathrm{Ca}^{2+}$ oscillations present in cortex glia in the ventral nerve cord in live, undissected larvae (Fig. 5A; Movie 4). We analyzed cortex glial $\mathrm{Ca}^{2+}$ oscillations with repo-Gal4 because this driver produced the highest expression of UAS-myrGCaMP5 and 

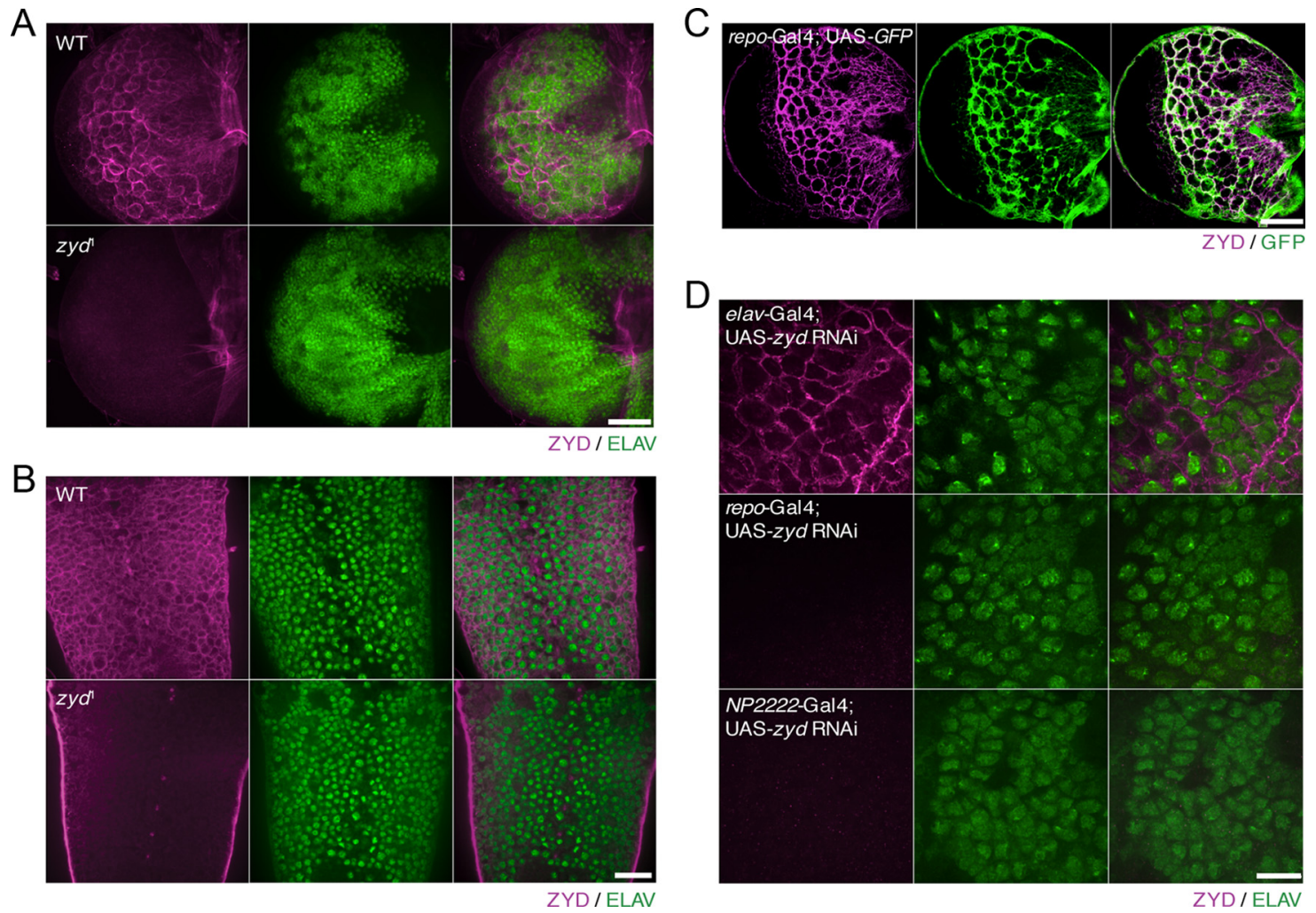

Figure 3. ZYD is expressed in cortex glia. $\boldsymbol{A}$, One hemisphere of the larval CNS in WT and zyd ${ }^{1}$ stained with antisera to ZYD (purple) and ELAV (green), which labels neuronal nuclei. ZYD immunoreactivity outlines large chambers in the outer cortex where glial ensheathment of secondary neurons has not occurred. Scale bar, $40 \mu \mathrm{m}$. $\boldsymbol{B}, 0$ ptical section within the ventral cortex of the VNC in WT and zyd ${ }^{1}$ third instar larvae. ZYD staining encapsulates individual neuronal soma. Scale bar, $20 \mu \mathrm{m}$. C, CNS stained with ZYD antisera in larvae expressing pan-glial GFP. Scale bar, $40 \mu \mathrm{m}$. D, Optical section of the CNS in larvae expressing pan-neuronal (elav-Gal4), pan-glial (repo-Gal4), or cortex glial (NP2222-Gal4) zyd RNAi. Scale bar, $10 \mu \mathrm{m}$.
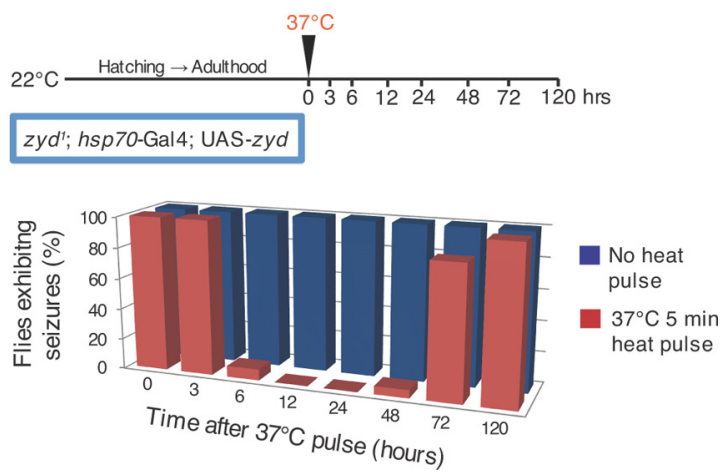

Figure 4. Adult-specific rescue of zyd mutants by conditional transgene expression rapidly reduces seizure susceptibility. Expression of UAS-zyd was controlled with the heat-inducible hsp70-Gal4 driver that is not expressed at room temperature and is activated above $30^{\circ} \mathrm{C} . z y d^{1}$ mutants were reared at $22^{\circ} \mathrm{C}$ until adulthood ( $2 \mathrm{~d}$ posteclosion), then exposed to a brief $37^{\circ} \mathrm{C}$ heat pulse. TS seizure susceptibility was strongly reduced in zyd ${ }^{1}$ mutants $6 \mathrm{~h}$ after transgene expression with hsp70-Gal4 (red bars). Genetically identical controls not receiving a heat pulse exhibited seizures at all time points (blue bars). $n=30$ flies/time point.

cortex glia are easily identified by morphology in the ventral nerve cord. However, expression of UAS-myrGCaMP5 with the cortex glial specific drivers NP2222-Gal4 and NP577-Gal4 revealed similar $\mathrm{Ca}^{2+}$ oscillatory activity. Standard fillet dissection of myrGCaMP5expressing larvae in external salines commonly used for electrophysiological recording (HL3.1) (Jan and Jan, 1976; Feng et al., 2004) caused rapid reduction in the frequency of glial $\mathrm{Ca}^{2+}$ transients. Cortex glial $\mathrm{Ca}^{2+}$ transients were consistently eliminated within 10 to 20 min of dissection despite extreme care taken to prevent damage to the CNS. Therefore, to ensure that the glial $\mathrm{Ca}^{2+}$ signals we re- corded were reflective of nonpathological in vivo activity, we performed all imaging experiments in live, undissected larvae gently pressed under a coverslip to reduce movement.

Cortex glial $\mathrm{Ca}^{2+}$ transients occur in small microdomains $\sim 4.35 \pm 0.26 \mu \mathrm{m}^{2}(n=40)$ and appeared to recur frequently in the same region (Fig. $5 B$ ), suggesting the presence of specialized structural or functional glial subdomains. The duration of each glial $\mathrm{Ca}^{2+}$ transient was $1.35 \pm 0.08 \mathrm{~s}$ and exhibited a mean $\Delta F / F_{\text {avg }}$ of $35.4 \pm 2.7 \%(n=40) . \mathrm{Ca}^{2+}$ transients generally arose within a small part of the cortex glial sheath surrounding a single neuronal soma (Fig. $5 \mathrm{D}, E$ ), although occasional $\mathrm{Ca}^{2+}$ waves appeared to pass through glial membrane encompassing multiple neurons. As a single cortex glial cell of the early larval ventral nerve cord encompasses dozens of neurons (Ito et al., 1995), it is unclear whether the observed $\mathrm{Ca}^{2+}$ waves pass between neighboring glia.

Microdomain cortex glial $\mathrm{Ca}^{2+}$ transients are completely absent in $z y d^{1}$ mutants at room temperature (Fig. 5C; Movie 5). However, baseline myrGCaMP5 fluorescence within the cortex glial network is significantly greater in $z y d^{1}$ mutants compared with wild-type controls (Fig. $5 F, G$ ), indicating glial intracellular $\mathrm{Ca}^{2+}$ is constitutively elevated in $z y d^{1}$ mutants. At the restrictive temperature of $38^{\circ} \mathrm{C}$, intracellular $\mathrm{Ca}^{2+}$ remains significantly elevated in $z y d^{1}$ cortex glia relative to wild type, although average myrGCaMP5 fluorescence increases in both wild-type and $z y d^{1}$ mutant glia with increasing temperature (Fig. 5G). The effect of hyperthermia on resting intracellular $\mathrm{Ca}^{2+}$ has been observed previously in Drosophila nerve terminals (Klose et al., 2009), and is thought to be due to a reduction in ATP-dependent $\mathrm{Ca}^{2+}$ clearance. In addition to constitutively elevated glial intracellular 

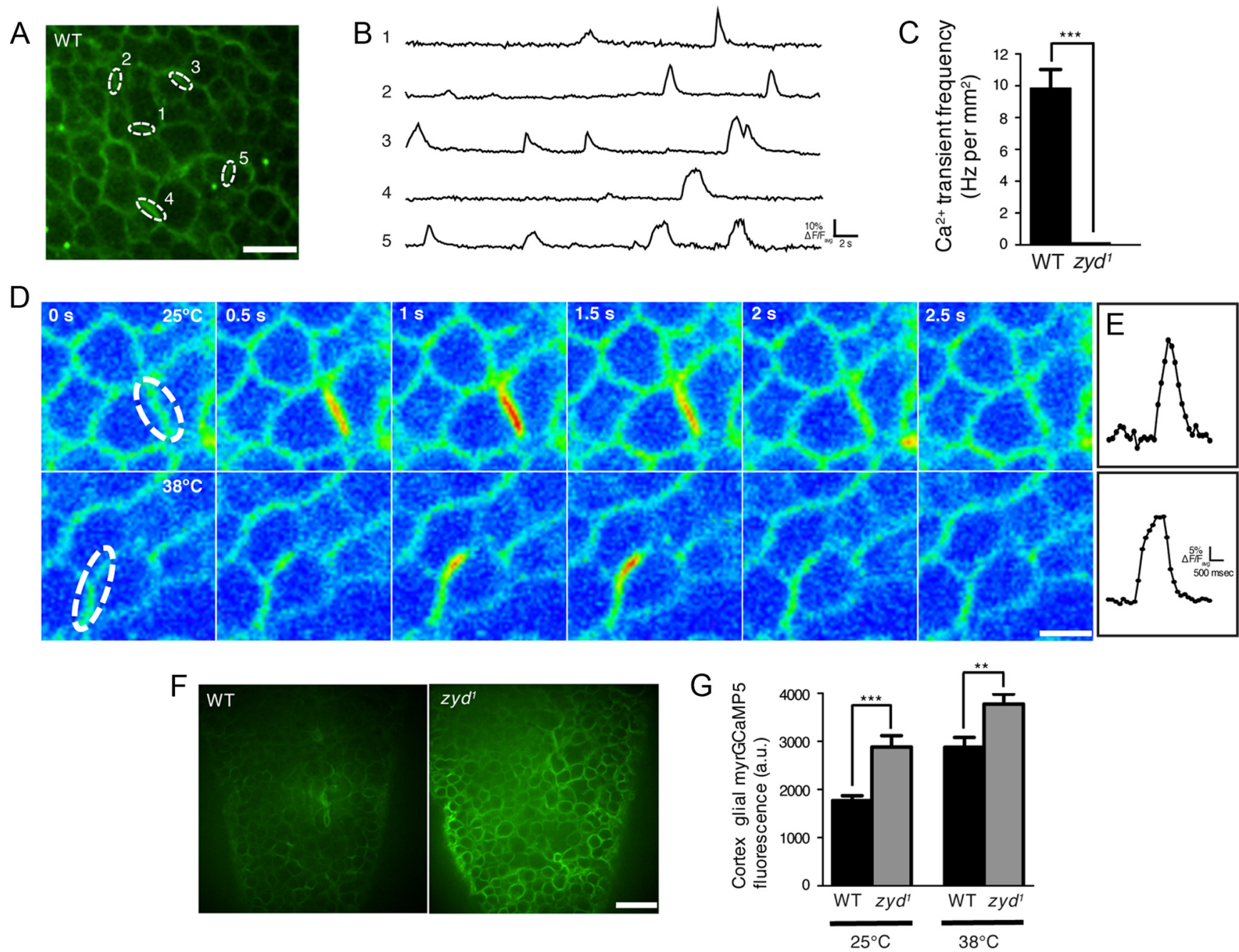

Figure 5. Microdomain $\mathrm{Ca}^{2+}$ oscillations in cortex glia require ZYD. $A, \mathrm{Ca}^{2+}$ transients occur in small regions of cortex glial membrane in the live larval ventral nerve cord. Scale bar, $10 \mu \mathrm{m}$. MyrGCaMP5 fluorescence $\left(\Delta F / F_{\text {avg }}\right)$ is shown for indicated regions in $B$. C, Frequency of microdomain $\mathrm{Ca}^{2+}$ transients in VNC cortex glia for wild-type and zyd ${ }^{1}$ mutants at $25^{\circ} \mathrm{C}$. $n=7$ larvae/genotype. $\boldsymbol{D}$, Time-lapse image series of a single cortex glial $\mathrm{Ca}^{2+}$ oscillation at $25^{\circ} \mathrm{C}$ and $38^{\circ} \mathrm{C}$ in wild-type larvae. Scale bar, $4 \mu \mathrm{m} . \boldsymbol{E}, \mathrm{MyrGCaMP5}$ fluorescence $\left(\Delta F / F_{\text {avg }}\right)$ for the regions indicated in the first panels of $\boldsymbol{D} . \boldsymbol{F}$, Representative images of myrGCamP5 fluorescence intensity in wild-type and zyd ${ }^{1}$ at $25^{\circ} \mathrm{C} . \mathrm{Scale}$ bar, $20 \mu \mathrm{m} . \boldsymbol{G}$, Average myrGCaMP5 fluorescence in cortex glia of wild-type and $z y d^{1}$ at $25^{\circ} \mathrm{C}$ and $38^{\circ} \mathrm{C} . n=10$ larvae/condition. Error bars represent the SEM. $t$ test: ${ }^{* * *} p<0.001,{ }^{* *} p<0.01$.

$\mathrm{Ca}^{2+}, z y d^{1}$ mutants fail to exhibit microdomain $\mathrm{Ca}^{2+}$ oscillations at either room temperature or $38^{\circ} \mathrm{C}(n=10$ larvae), while wild-type controls exhibit frequent and dynamic microdomain $\mathrm{Ca}^{2+}$ fluctuations under both conditions.

\section{Acute cortex glial $\mathrm{Ca}^{2+}$ influx via ectopic TRPA1 activation triggers seizures}

Given that $z y d$ mutants lack microdomain $\mathrm{Ca}^{2+}$ transients and also exhibit increased global intracellular $\mathrm{Ca}^{2+}$, we hypothesized that seizures may arise in $z y d$ mutants due to either a constitutive lack of regulated glial $\mathrm{Ca}^{2+}$ signaling, or acute elevation of glial $\mathrm{Ca}^{2+}$ triggered by environmental stimuli. To discriminate between these two possibilities, we investigated the requirement for acute glial $\mathrm{Ca}^{2+}$ regulation in vivo by ectopic expression of the heat-activated dTRPA1 cation channel. Drosophila TRPA1 is normally restricted to a small number of thermotactic neurons and is permeable to $\mathrm{Ca}^{2+}$ influx with moderate increases in temperature (Rosenzweig et al., 2005; Hamada et al., 2008) (Fig. 6A). Previous studies have shown that ectopic expression of dTRPA1 in motor neurons elicits action potentials above $26^{\circ} \mathrm{C}$ and does not affect mem- brane properties at $22^{\circ} \mathrm{C}$ (Pulver et al., 2009), indicating dTRPA1 is a useful tool for acutely manipulating intracellular $\mathrm{Ca}^{2+}$. We assessed the behavioral effect of activating dTRPA1 in cortex glia, and found that adult flies exhibited strong, immobilizing seizures within seconds of a temperature shift to $30^{\circ} \mathrm{C}$ (Movie 6). These seizures were similar in onset and appearance to seizures observed in animals expressing panneuronal dTRPA1 with elav-Gal4. Interestingly, pan-glial dTRPA1 activation with repo-Gal4 causes immediate paralysis in adult flies, possibly due to impairment of blood-brain barrier glia, which are required for axonal insulation and action potential conduction (Baumgartner et al., 1996).

We recorded central pattern generator activity in the muscle of larvae expressing ectopic dTRPA1 while applying a temperature ramp, and found that cortex glial dTRPA1 larvae exhibited increased motor neuron bursting at $27^{\circ} \mathrm{C}$, followed by continuous seizure activity at $30^{\circ} \mathrm{C}$ (Fig. $6 \mathrm{~B}$ ). Similar seizure progression was observed in pan-neuronal dTRPA1 expressing larvae. These results indicate that acute, in vivo disruption of $\mathrm{Ca}^{2+}$ regulation in cortex glia is sufficient to initiate neuronal seizure activity. 


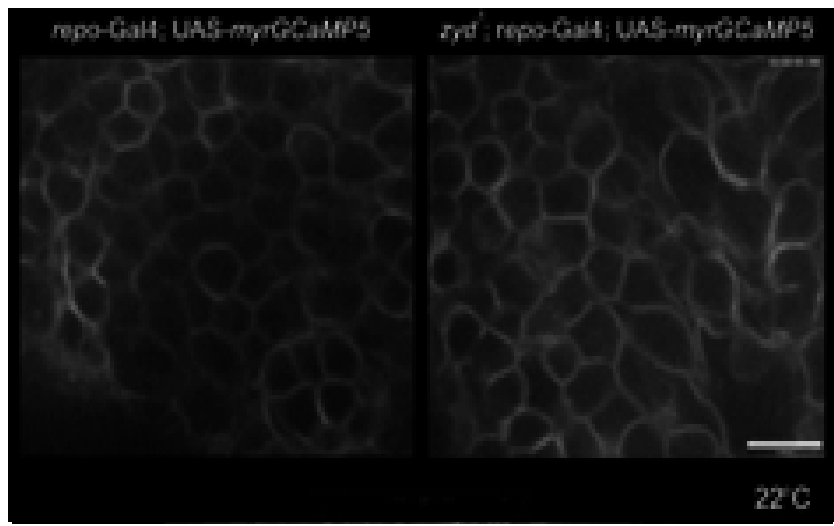

Movie 4. Cortex glial $\mathrm{Ca}^{2+}$ oscillations detected in vivo with myrGCaMP5. $\mathrm{Ca}^{2+}$ oscillations within cortex glia in the ventral nerve cord of an undissected wild-type second instar larvae. Video speed is $2 \times$ real time.

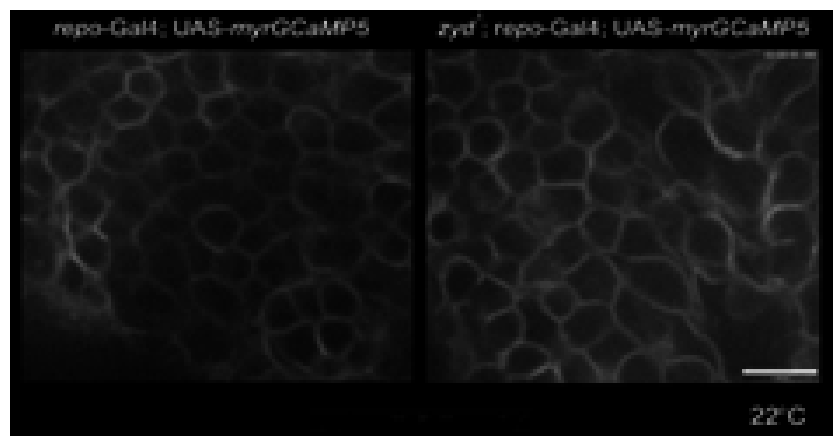

Movie 5. Cortex glial $\mathrm{Ca}^{2+}$ oscillations are absent in zyd mutants. Microdomain $\mathrm{Ca}^{2+}$ transients are present in wild-type, but not zyd ${ }^{1}$ mutant, second instar larvae. Images were acquired through the cuticle of an undissected second instar larvae. Video speed is $3 \times$ real time.

\section{Glial expression of calmodulin is required for seizure initiation in $z y d$ mutants}

To probe the mechanism by which altered glial $\mathrm{Ca}^{2+}$ regulation in $z y d^{1}$ mutants induces seizures, we performed an RNAi screen for suppression of $z y d^{1}$ mutant TS seizures. We knocked down candidate genes in $z y d^{1}$ mutants that are implicated in vesicular trafficking and regulation, given recent evidence that $\mathrm{Ca}^{2+}$ dependent exocytosis in mammalian glia alters neuronal excitability (Parpura and Zorec, 2010). We found that pan-glial knockdown of calmodulin (cam) in $z y d^{1}$ mutants fully suppresses TS seizures in both larvae and adults (Fig. $7 A, C$ ), indicating a $\mathrm{Ca}^{2+} /$ calmodulin-dependent glial signaling pathway is required for seizure initiation. Calmodulin is a an essential $\mathrm{Ca}^{2+}$-binding protein that regulates multiple $\mathrm{Ca}^{2+}$-dependent cellular processes and is expressed in Drosophila glia (Altenhein et al., 2006), although its role in glia is unknown. We verified that expression of cam RNAi reduces calmodulin protein by Western blot using the eye-specific driver $\mathrm{gmr}$-Gal4 (Fig. 7B). Knockdown of cam with repo-Gal4 did not significantly reduce total calmodulin brain protein, likely due to high expression of calmodulin in the Drosophila compound eye and neuronal tissue (Chintapalli et al., 2007).

Given that calmodulin is required for seizures in $z y d$ mutants, we asked whether knockdown of calmodulin could suppress paralysis observed in animals expressing ectopic glial dTRPA1. We observed that acute, pan-glial $\mathrm{Ca}^{2+}$ influx via dTRPAl causes immediate paralysis in adult flies (Movie 6) that persists until animals are returned to room temperature. Concomitant expres- sion of UAS-cam RNAi significantly lengthens the time required to induce paralysis in glial dTRPAl adults at $30^{\circ} \mathrm{C}$, and the majority of flies were found to recover from paralysis during incubation at the restrictive temperature (Fig. 7D). We also observed that pan-glial dTRPA1 flies expressing cam RNAi exhibited wildtype activity levels immediately upon return to room temperature, whereas control dTRPA1 flies remained immobilized for several minutes after a $3 \mathrm{~min}$ exposure to $30^{\circ} \mathrm{C}$. The suppression of glial dTRPA1-induced paralysis was not due to a titration of available Gal4, as expression of other UAS-RNAi hairpins did not produce a similar rescue effect. The strong suppression of glial dTRPA1-induced paralysis by calmodulin knockdown indicates that calmodulin plays a central role in mediating a glial $\mathrm{Ca}^{2+}$ dependent process that acutely affects nervous system function.

\section{Discussion}

The findings reported here indicate that mutation of the NCKX $z y d$ eliminates microdomain $\mathrm{Ca}^{2+}$ oscillations in glia and predisposes animals to seizures. In vivo imaging of live, unanesthetized animals revealed that Drosophila cortex glia exhibit rapid and frequent microdomain $\mathrm{Ca}^{2+}$ fluctuations in discrete domains encompassing neuronal cell bodies. Disruption of cortex glial $\mathrm{Ca}^{2+}$ transients by mutation of $z y d$ enhances seizure susceptibility to several environmental triggers, which is restored upon acute expression of ZYD in the adult CNS. Our results also indicate that a $\mathrm{Ca}^{2+} /$ calmodulin-dependent signaling pathway underlies acute glial modulation of neuronal activity. Previous studies have generated conflicting data regarding the importance of astrocytic $\mathrm{Ca}^{2+}$ signaling to neuronal physiology (Fiacco et al., 2007; Petravicz et al., 2008; Agulhon et al., 2010; Gómez-Gonzalo et al., 2010; Henneberger et al., 2010). Our data demonstrate in vivo that endogenous microdomain $\mathrm{Ca}^{2+}$ oscillations in glia acutely influence neuronal function, and are involved in the pathophysiology of seizures in Drosophila.

\section{The NCKX ZYD is required for endogenous glial}

\section{$\mathrm{Ca}^{2+}$ oscillations}

We isolated mutations in the NCKX zyd in a screen for temperature-sensitive behavioral phenotypes in Drosophila. This type of forward genetic screen has previously enabled identification of conditional alleles in genes required for nervous system function, including the voltage-gated $\mathrm{Na}^{+}, \mathrm{K}^{+}$, and $\mathrm{Ca}^{2+}$ channels (para, shaw, cac), proteins involved in synaptic vesicle exocytosis (NSF, syntaxin), and endocytosis (dynamin, dap160), among others. Surprisingly, we found that $z y d$ is not expressed in neurons, but is localized to cortex glia, a large population of cells in the CNS that associate closely with neuronal cell bodies. Cortex glia ensheath neuronal soma with extremely thin membrane projections and form a honeycombed network in the brain (Pereanu et al., 2005), yet the function of these cells in modulation or support of acute neuronal signaling is not understood.

We found that ZYD is required for microdomain $\mathrm{Ca}^{2+}$ transients in cortex glia, as $z y d$ mutant glia fail to exhibit small $\mathrm{Ca}^{2+}$ oscillations observed in vivo in wild-type animals. $z y d$ has been shown to encode a functional $\mathrm{K}^{+}$-dependent $\mathrm{Na}^{+} / \mathrm{Ca}^{2+}$ exchanger (Winkfein et al., 2004), and is homologous to a family of vertebrate NCKX exchangers that have been well described for their role in regulating $\mathrm{Ca}^{2+}$ levels in rod photoreceptors (Schnetkamp, 2004) and cortical neurons (Li et al., 2006). In contrast to the slower, high-affinity $\mathrm{Ca}^{2+}$ ATPases that are thought to fine tune resting $\mathrm{Ca}^{2+}$ concentration in the nanomolar range, NCKX transporters rapidly extrude $\mathrm{Ca}^{2+}$ that reaches micromolar con- 


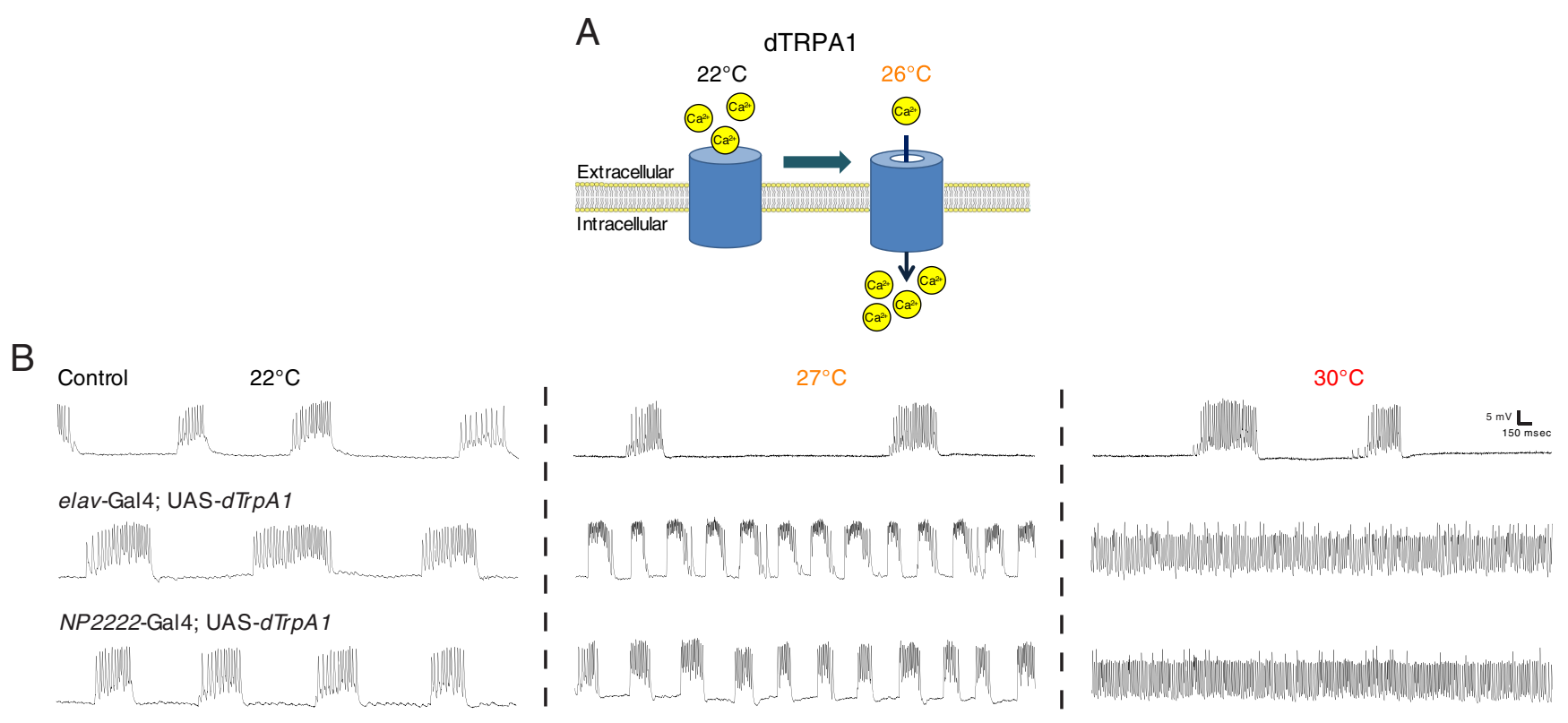

Figure 6. Acute $\mathrm{Ca}^{2+}$ dysregulation in cortex glia causes seizures. $\boldsymbol{A}$, The heat-activated dTRPA1 cation channel is closed at $22^{\circ} \mathrm{C}$ and open at temperatures $\geq 26^{\circ} \mathrm{C}$, allowing $\mathrm{Ca}^{2+}$ influx. $\boldsymbol{B}$, Ectopic expression of dTRPA1 in neurons (with elav-Gal4) and in cortex glia (with NP2222-Gal4) triggers seizure-like output from the central pattern generator. Voltage traces were recorded from the third instar larval muscle during application of a temperature ramp. Preparations were held at the indicated temperature for 2 min before recording. $n>6$ larvae per genotype.

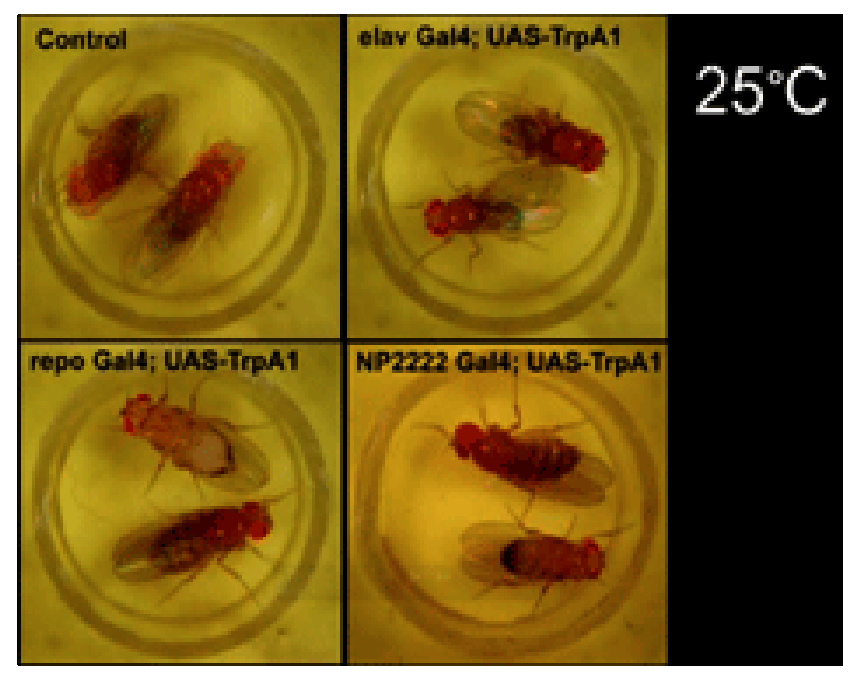

Movie 6. Acute dysregulation of cortex glial $\mathrm{Ca}^{2+}$ causes seizures. dTRPA1-mediated $\mathrm{Ca}^{2+}$ influx into cortex glia (with NP2222-Gal4) causes rapid-onset seizures in adult flies, similar in time course to pan-neuronal dTRPA1 activation (with elav-Gal4). Pan-glial dTRPA1 expression (with repo-Gal4) causes paralysis. Video speed is $2 \times$ real time.

centrations (Altimimi and Schnetkamp, 2007) and are activated during sharp peaks in intracellular $\mathrm{Ca}^{2+}$.

The mutations we isolated in zyd are likely hypomorphic rather than null alleles. Glial knockdown of $z y d$ by RNAi is semilethal, and adult escapers are ataxic and die within several days, whereas the $z y d$ mutants identified in our screen are adult viable and exhibit no obvious behavioral defects at room temperature. Interestingly, the $z y d^{2}$ mutant carries an amino acid change (alanine-80-valine) at the same residue found at a polymorphic site in the NCKX5 family member that regulates skin color (Lamason et al., 2005). NCKX5 is unlike other mammalian NCKX isoforms in that it is not expressed in the brain, but is present in skin cells, where it regulates melanosome maturation. The alanine-111-threonine variant of NCKX5 is found in European-
A

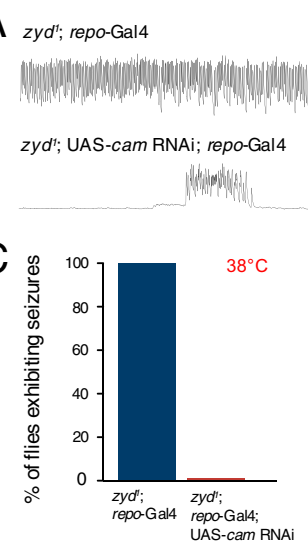

$38^{\circ} \mathrm{C}$

B

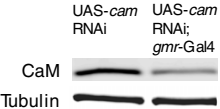

Tubulin

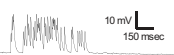

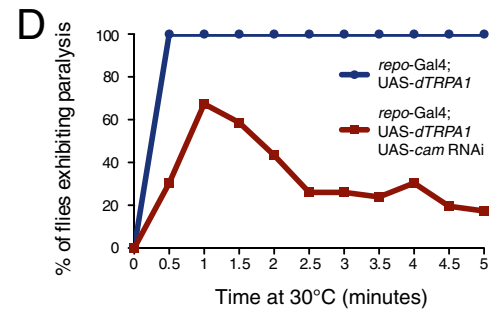

Figure 7. Knockdown of calmodulin suppresses seizures in zyd mutants and paralysis due to ectopic glial TRPA1 activation. $A$, Central pattern generator activity recorded in larval muscle in control and following pan-glial expression of cam RNAi in zyd ${ }^{1}$ mutants at $38^{\circ} \mathrm{C}$. B, Western blot of adult heads expressing cam RNAi in the eye with gmr-Gal4. Tubulin was used as loading control. C, Quantification of seizure suppression in adult zyd ${ }^{1}$ animals expressing pan-glial cam RNAi. $n=100$ flies/genotype. $\boldsymbol{D}$, Time course of paralysis upon exposure to $30^{\circ} \mathrm{C}$ in adult flies expressing pan-glial dTRPA1 (blue line) and flies expressing pan-glial dTRPA1 and cam RNAi (red line). $n>50$ flies/genotype.

American populations with lighter skin color and causes substantial reduction in exchanger activity (Ginger et al., 2008). The closest mammalian homologs to Drosophila ZYD are NCKX3 and NCKX4, which are expressed broadly in the CNS but are relatively uncharacterized (Lytton et al., 2002). Recently, mRNA from NCKX3 was found to be highly expressed in acutely isolated Bergmann glial cells from the adult mouse cerebellum (Koirala and Corfas, 2010), and NCKX2 expression was identified in oligodendrocytes (Cahoy et al., 2008), indicating that mammalian NCKX exchangers may regulate $\mathrm{Ca}^{2+}$ activity in these glia as well.

\section{Dysregulation of $\mathrm{Ca}^{2+}$ in cortical glia promotes seizures}

Seizures in $z y d$ mutants are triggered by temperature shifts (both high and low) and mechanical stimulation. How does disruption 
of ZYD predispose animals to seizures? We found that in addition to lacking microdomain $\mathrm{Ca}^{2+}$ transients, $z y d$ mutant glia also exhibit constitutively elevated intracellular $\mathrm{Ca}^{2+}$ at room temperature and the seizure-inducing temperature of $38^{\circ} \mathrm{C}$. One possibility is that the $z y d$ mutant nervous system is "primed" for seizures due to deregulation of a $\mathrm{Ca}^{2+}$-dependent glial process that modulates neuronal activity. Increasing temperature has been shown to enhance neuronal activity in Drosophila (Peng et al., 2007), possibly inducing runaway excitation in $z y d$ mutants. Another possible model is that stressful environmental stimuli trigger seizures by acutely increasing intracellular glial $\mathrm{Ca}^{2+}$. We found that hyperthermia causes a global increase in glial $\mathrm{Ca}^{2+}$ that is significantly elevated in $z y d$ mutants relative to wild type. This observation is consistent with previous studies on hyperthermia-induced $\mathrm{Ca}^{2+}$ increase in Drosophila nerve terminals (Klose et al., 2009). Although zyd mutant glia exhibit elevated intracellular $\mathrm{Ca}^{2+}$ at room temperature, additional $\mathrm{Ca}^{2+}$ elevation at $38^{\circ} \mathrm{C}$ may push the cell past a threshold that triggers a seizure-inducing process. Consistent with this hypothesis is our observation that acute cortex glial $\mathrm{Ca}^{2+}$ influx mediated by ectopic expression of dTRPA1 causes immediate seizures in adult animals. The requirement for regulated glial $\mathrm{Ca}^{2+}$ signaling in the mature $\mathrm{CNS}$ suggests that seizures in $z y d$ mutants arise due to acute glial dysfunction.

Given that ZYD is not required in surface glia that constitute the blood-brain barrier, we can rule out a defect in ion balance in these glial subtypes. ZYD is also not required in ensheathing glia, which insulate axons, or neuropil glia, which associate with synapses. We find that ZYD expression is restricted to cortical glia that interact specifically with neuronal cell bodies, forming glial subdivisions in the CNS that are reminiscent of the spatial segregation of mammalian astrocytes (Awasaki et al., 2008). As such, $\mathrm{Ca}^{2+}$ oscillations in cortex glia may normally regulate the activity of small, interconnected neuronal networks. A second clue to how glial $\mathrm{Ca}^{2+}$ oscillations regulate excitability is the observation that calmodulin is required in glia for seizure induction in $z y d^{1}$ mutants. Calmodulin acts as a $\mathrm{Ca}^{2+}$ sensor in many signaling pathways and is predicted to have a limited spatial range of action (Solà et al., 2001; Saucerman and Bers, 2012), suggesting calmodulin mediates a local signaling function in cortex glial $\mathrm{Ca}^{2+}$ microdomains.

\section{A role for glia in seizure pathophysiology}

These data suggest a direct role for glia in seizure generation, indicating that at least some epileptic pathologies might have a glial rather than neuronal origin. Evidence for a non-neuronal induction of seizures has been suggested in several cases, including in situ studies correlating elevated astrocytic $\mathrm{Ca}^{2+}$ oscillations with seizure initiation (Tashiro et al., 2002; Gómez-Gonzalo et al., 2010) and in vivo work demonstrating several anti-epilepsy drugs reduce glial $\mathrm{Ca}^{2+}$ oscillations (Tian et al., 2005). The observation that astrocytic, $\mathrm{Ca}^{2+}$-dependent glutamate release elicits synchronous currents in neighboring neurons suggests a possible mechanism by which glia may control the excitability of small neuronal circuits (Angulo et al., 2004; Fellin et al., 2004; Tian et al., 2005). However, synchronous inward neuronal currents produced by astrocytic $\mathrm{Ca}^{2+}$ signaling were found to be dispensable for the generation of epileptiform activity in vitro (Fellin et al., 2006), suggesting glia may play more of a modulatory role in seizure activity. The identification of a glial-specific gene $(z y d)$ responsible for an epileptic phenotype suggests that at least in some cases, $\mathrm{Ca}^{2+}$ dysregulation in an astrocyte-like cell population is sufficient to initiate a seizure.
In summary, these findings demonstrate a direct role for glial $\mathrm{Ca}^{2+}$ in regulating neuronal seizure susceptibility. Additional genetic screens for suppressors of the temperature-sensitive $z y d$ seizure phenotype should uncover how $\mathrm{Ca}^{2+}$ oscillations in glia signal to neighboring neurons, as well as generate new insights into the pathophysiology of epilepsy.

\section{References}

Agulhon C, Petravicz J, McMullen AB, Sweger EJ, Minton SK, Taves SR, Casper KB, Fiacco TA, McCarthy KD (2008) What is the role of astrocyte calcium in neurophysiology? Neuron 59:932-946. CrossRef Medline

Agulhon C, Fiacco TA, McCarthy KD (2010) Hippocampal short- and longterm plasticity are not modulated by astrocyte $\mathrm{Ca} 2+$ signaling. Science 327:1250-1254. CrossRef Medline

Akerboom J, Chen TW, Wardill TJ, Tian L, Marvin JS, Mutlu S, Calderón NC, Esposti F, Borghuis BG, Sun XR, Gordus A, Orger MB, Portugues R, Engert F, Macklin JJ, Filosa A, Aggarwal A, Kerr RA, Takagi R, Kracun S, et al. (2012) Optimization of a GCaMP calcium indicator for neural activity imaging. J Neurosci 32:13819-13840. CrossRef Medline

Altenhein B, Becker A, Busold C, Beckmann B, Hoheisel JD, Technau GM (2006) Expression profiling of glial genes during Drosophila embryogenesis. Dev Biol 296:545-560. CrossRef Medline

Altimimi HF, Schnetkamp PP (2007) Na+/Ca2+-K+ exchangers (NCKX): functional properties and physiological roles. Channels (Austin) 1:62-69. Medline

Angulo MC, Kozlov AS, Charpak S, Audinat E (2004) Glutamate released from glial cells synchronizes neuronal activity in the hippocampus. J Neurosci 24:6920-6927. CrossRef Medline

Awasaki T, Lai SL, Ito K, Lee T (2008) Organization and postembryonic development of glial cells in the adult central brain of Drosophila. J Neurosci 28:13742-13753. CrossRef Medline

Banerjee S, Pillai AM, Paik R, Li J, Bhat MA (2006) Axonal ensheathment and septate junction formation in the peripheral nervous system of Drosophila. J Neurosci 26:3319-3329. CrossRef Medline

Baumgartner S, Littleton JT, Broadie K, Bhat MA, Harbecke R, Lengyel JA, Chiquet-Ehrismann R, Prokop A, Bellen HJ (1996) A Drosophila neurexin is required for septate junction and blood-nerve barrier formation and function. Cell 87:1059-1068. CrossRef Medline

Beckervordersandforth RM, Rickert C, Altenhein B, Technau GM (2008) Subtypes of glial cells in the Drosophila embryonic ventral nerve cord as related to lineage and gene expression. Mech Dev 125:542-557. CrossRef Medline

Brand AH, Manoukian AS, Perrimon N (1994) Ectopic expression in Drosophila. Methods Cell Biol 44:635-654. CrossRef Medline

Bushong EA, Martone ME, Jones YZ, Ellisman MH (2002) Protoplasmic astrocytes in CA1 stratum radiatum occupy separate anatomical domains. J Neurosci 22:183-192. Medline

Cahoy JD, Emery B, Kaushal A, Foo LC, Zamanian JL, Christopherson KS, Xing Y, Lubischer JL, Krieg PA, Krupenko SA, Thompson WJ, Barres BA (2008) A transcriptome database for astrocytes, neurons, and oligodendrocytes: a new resource for understanding brain development and function. J Neurosci 28:264-278. CrossRef Medline

Chintapalli VR, Wang J, Dow JA (2007) Using FlyAtlas to identify better Drosophila melanogaster models of human disease. Nat Genet 39: 715-720. CrossRef Medline

Doherty J, Logan MA, Taşdemir OE, Freeman MR (2009) Ensheathing glia function as phagocytes in the adult Drosophila brain. J Neurosci 29:4768 4781. CrossRef Medline

Dumstrei K, Wang F, Hartenstein V (2003) Role of DE-cadherin in neuroblast proliferation, neural morphogenesis, and axon tract formation in Drosophila larval brain development. J Neurosci 23:3325-3335. Medline

Fellin T, Pascual O, Gobbo S, Pozzan T, Haydon PG, Carmignoto G (2004) Neuronal synchrony mediated by astrocytic glutamate through activation of extrasynaptic NMDA receptors. Neuron 43:729-743. CrossRef Medline

Fellin T, Gomez-Gonzalo M, Gobbo S, Carmignoto G, Haydon PG (2006) Astrocytic glutamate is not necessary for the generation of epileptiform neuronal activity in hippocampal slices. J Neurosci 26:9312-9322. CrossRef Medline

Feng Y, Ueda A, Wu CF (2004). A modified minimal hemolymph-like solution, HL3.1, for physiological recordings at the neuromuscular junctions 
of normal and mutant Drosophila larvae. J Neurogenet 18:377-402. CrossRef Medline

Fiacco TA, Agulhon C, Taves SR, Petravicz J, Casper KB, Dong X, Chen J, McCarthy KD (2007) Selective stimulation of astrocyte calcium in situ does not affect neuronal excitatory synaptic activity. Neuron 54:611-626. CrossRef Medline

Fuentes-Medel Y, Logan MA, Ashley J, Ataman B, Budnik V, Freeman MR (2009) Glia and muscle sculpt neuromuscular arbors by engulfing destabilized synaptic boutons and shed presynaptic debris. PLoS Biol 7:e1000184. CrossRef Medline

Ginger RS, Askew SE, Ogborne RM, Wilson S, Ferdinando D, Dadd T, Smith AM, Kazi S, Szerencsei RT, Winkfein RJ, Schnetkamp PP, Green MR (2008) SLC24A5 encodes a trans-Golgi network protein with potassiumdependent sodium-calcium exchange activity that regulates human epidermal melanogenesis. J Biol Chem 283:5486-5495. CrossRef Medline

Gómez-Gonzalo M, Losi G, Chiavegato A, Zonta M, Cammarota M, Brondi M, Vetri F, Uva L, Pozzan T, de Curtis M, Ratto GM, Carmignoto G (2010) An excitatory loop with astrocytes contributes to drive neurons to seizure threshold. PLoS Biol 8:e1000352. CrossRef Medline

Guan Z, Saraswati S, Adolfsen B, Littleton JT (2005) Genome-wide transcriptional changes associated with enhanced activity in the Drosophila nervous system. Neuron 48:91-107. CrossRef Medline

Halassa MM, Fellin T, Takano H, Dong JH, Haydon PG (2007) Synaptic islands defined by the territory of a single astrocyte. J Neurosci 27: 6473-6477. CrossRef Medline

Hamada FN, Rosenzweig M, Kang K, Pulver SR, Ghezzi A, Jegla TJ, Garrity PA (2008) An internal thermal sensor controlling temperature preference in Drosophila. Nature 454:217-220. CrossRef Medline

Henneberger C, Papouin T, Oliet SH, Rusakov DA (2010) Long-term potentiation depends on release of D-serine from astrocytes. Nature 463: 232-236. CrossRef Medline

Hosoya T, Takizawa K, Nitta K, Hotta Y (1995) glial cells missing: a binary switch between neuronal and glial determination in Drosophila. Cell 82: 1025-1036. CrossRef Medline

Hoyle G, Williams M, Phillips C (1986) Functional morphology of insect neuronal cell-surface/glial contacts: the trophospongium. J Comp Neurol 246:113-128. CrossRef Medline

Ito K, Urban J, Technau G (1995) Distribution, classification, and development of Drosophila glial cells in the late embryonic and early larval ventral nerve cord. Roux's Arch Dev Biol 204:284-307. CrossRef

Jackson FR, Haydon PG (2008) Glial cell regulation of neurotransmission and behavior in Drosophila. Neuron Glia Biol 4:11-17. CrossRef Medline

Jan LY, Jan YN (1976) Properties of the larval neuromuscular junction in Drosophila melanogaster. J Physiol 262:189-214. Medline

Klassen T, Davis C, Goldman A, Burgess D, Chen T, Wheeler D, McPherson J, Bourquin T, Lewis L, Villasana D, Morgan M, Muzny, Gibbs R, Noebels J (2011) Exome sequencing of ion channel genes reveals complex profiles confounding personal risk assessment in epilepsy. Cell 145:1036-1048. CrossRef Medline

Klose MK, Boulianne GL, Robertson RM, Atwood HL (2009) Role of ATPdependent calcium regulation in modulation of Drosophila synaptic thermotolerance. J Neurophysiol 102:901-913. CrossRef Medline

Koirala S, Corfas G (2010) Identification of novel glial genes by single-cell transcriptional profiling of Bergmann glial cells from mouse cerebellum. PLoS One 5:e9198. CrossRef Medline

Lamason RL, Mohideen MA, Mest JR, Wong AC, Norton HL, Aros MC, Jurynec MJ, Mao X, Humphreville VR, Humbert JE, Sinha S, Moore JL, Jagadeeswaran P, Zhao W, Ning G, Makalowska I, McKeigue PM, O'donnell D, Kittles R, Parra EJ, et al. (2005) SLC24A5, a putative cation exchanger, affects pigmentation in zebrafish and humans. Science 310: 1782-1786. CrossRef Medline

Li XF, Kiedrowski L, Tremblay F, Fernandez FR, Perizzolo M, Winkfein RJ, Turner RW, Bains JS, Rancourt DE, Lytton J (2006) Importance of K+dependent $\mathrm{Na}+/ \mathrm{Ca} 2+$-exchanger 2, NCKX2, in motor learning and memory. J Biol Chem 281:6273-6282. CrossRef Medline

Lindquist S (1986) The heat-shock response. Annu Rev Biochem 55: 1151-1191. CrossRef Medline
Lytton J, Li XF, Dong H, Kraev A (2002) K+-dependent Na+/Ca2+ exchangers in the brain. Ann N Y Acad Sci 976:382-393. CrossRef Medline

Ng FS, Tangredi MM, Jackson FR (2011) Glial cells physiologically modulate clock neurons and circadian behavior in a calcium-dependent manner. Curr Biol 21:625-634. CrossRef Medline

Parpura V, Zorec R (2010) Gliotransmission: Exocytotic release from astrocytes. Brain Res Rev 63:83-92. CrossRef Medline

Pavlidis P, Tanouye MA (1995) Seizures and failures in the giant fiber pathway of Drosophila bang-sensitive paralytic mutants. J Neurosci 15:5810-5819. Medline

Peng IF, Berke BA, Zhu Y, Lee WH, Chen W, Wu CF (2007) Temperaturedependent developmental plasticity of Drosophila neurons: cellautonomous roles of membrane excitability, $\mathrm{Ca}^{2+}$ influx, and cAMP signaling. J Neurosci 27:12611-12622. CrossRef Medline

Pereanu W, Shy D, Hartenstein V (2005) Morphogenesis and proliferation of the larval brain glia in Drosophila. Dev Biol 283:191-203. CrossRef Medline

Petravicz J, Fiacco TA, McCarthy KD (2008) Loss of IP3 receptordependent $\mathrm{Ca}^{2+}$ increases in hippocampal astrocytes does not affect baseline CA1 pyramidal neuron synaptic activity. J Neurosci 28:4967-4973. CrossRef Medline

Pulver SR, Pashkovski SL, Hornstein NJ, Garrity PA, Griffith LC (2009) Temporal dynamics of neuronal activation by Channelrhodopsin-2 and TRPA1 determine behavioral output in Drosophila larvae. J Neurophysiol 101:3075-3088. CrossRef Medline

Rosenzweig M, Brennan KM, Tayler TD, Phelps PO, Patapoutian A, Garrity PA (2005) The Drosophila ortholog of vertebrate TRPA1 regulates thermotaxis. Genes Dev 19:419-424. CrossRef Medline

Saucerman JJ, Bers DM (2012) Calmodulin binding proteins provide domains of local $\mathrm{Ca}^{2+}$ signaling in cardiac myocytes. J Mol Cell Cardiol 52:312-316. CrossRef Medline

Schnetkamp PP (2004) The SLC24 Na+/Ca2+-K+ exchanger family: vision and beyond. Pflugers Arch 447:683-688. CrossRef Medline

Shigetomi E, Kracun S, Khakh BS (2010) Monitoring astrocyte calcium microdomains with improved membrane targeted GCaMP reporters. Neuron Glia Biol 6:183-191. CrossRef Medline

Solà C, Barrón S, Tusell JM, Serratosa J (2001) The Ca2+/calmodulin system in neuronal hyperexcitability. Int J Biochem Cell Biol 33:439-455. CrossRef Medline

Spindler SR, Ortiz I, Fung S, Takashima S, Hartenstein V (2009) Drosophila cortex and neuropile glia influence secondary axon tract growth, pathfinding, and fasciculation in the developing larval brain. Dev Biol 334:355-368. CrossRef Medline

Stork T, Bernardos R, Freeman MR (2012) Analysis of glial cell development and function in Drosophila. Cold Spring Harb Protoc 2012:1-17. CrossRef Medline

Takata N, Hirase H (2008) Cortical layer 1 and layer 2/3 astrocytes exhibit distinct calcium dynamics in vivo. PLoS One 3:e2525. CrossRef Medline

Tashiro A, Goldberg J, Yuste R (2002) Calcium oscillations in neocortical astrocytes under epileptiform conditions. J Neurobiol 50:45-55. CrossRef Medline

Tian GF, Azmi H, Takano T, Xu Q, Peng W, Lin J, Oberheim N, Lou N, Wang X, Zielke HR, Kang J, Nedergaard M (2005) An astrocytic basis of epilepsy. Nat Med 11:973-981. CrossRef Medline

Wang X, Lou N, Xu Q, Tian GF, Peng WG, Han X, Kang J, Takano T, Nedergaard M (2006) Astrocytic Ca2+ signaling evoked by sensory stimulation in vivo. Nat Neurosci 9:816-823. CrossRef Medline

Winkfein RJ, Szerencsei RT, Kinjo TG, Kang K, Perizzolo M, Eisner L, Schnetkamp PP (2003) Scanning mutagenesis of the alpha repeats and of the transmembrane acidic residues of the human retinal cone $\mathrm{Na} / \mathrm{Ca}-\mathrm{K}$ exchanger. Biochemistry 42:543-552. CrossRef Medline

Winkfein RJ, Pearson B, Ward R, Szerencsei RT, Colley NJ, Schnetkamp PP (2004) Molecular characterization, functional expression and tissue distribution of a second NCKX Na+/Ca2 + -K+ exchanger from Drosophila. Cell Calcium 36:147-155. CrossRef Medline 